\title{
An Assessment of Community Health Needs Assessment (CHNA) Data Collection Related to Building Capacity for Sexual and Gender Marginalized (SGM) Individuals in Health Care Organizations ${ }^{1}$
}

\author{
John A. Grummel \\ Upper Iowa University \\ Jaime Collins \\ Southwest Health
}

This research examines $L G B T Q+$ data collection for Community Health Needs Assessments (CHNA) by Wisconsin Health care organizations as mandated by the Affordable Care Act, and whether data collection considered $L G B T Q+$ populations. If collected, it assesses what types of $L G B T Q+$ data was collected and how it was used and/or reported in the CHNA. Furthermore, a comparison by location (rural/urban) regarding whether there is a difference in likelihood that a health care organization would collect $L G B T Q^{+}$ data. The results of this study indicate that data collection is collected by approximately one-quarter of Wisconsin health care organizations for the purpose of their CHNAs and there is not a significant difference by location regarding inclusion of $L G B T Q+$ data.

Keywords: community health needs assessments, LGBTQ, health care, data collection

\section{INTRODUCTION}

Although the Affordable Care Act (ACA) greatly reduced the number of people in the United States without health care insurance, the lesbian, gay, bisexual, transgender, queer/questioning (LGBTQ) community still faces challenges in accessing high-quality health care (Boehmer, 2002; Denney, Gorman, \& Barrera, 2013; Gates, 2013; Joint Commission, 2011). Social, political, and cultural forces limit the capacity of health care organizations to adequately care for LGBTQ individuals by hindering the collection of robust data regarding LGBTQ individuals (Gates, 2017; Glasgow, 2019).

Kadour's (2005) dire warning that "data are a cornerstone of any public health system and the lack of data on sexual minorities correlates with the failure of public health to address this group's needs" still rings true today (p. 31). Though isolated efforts exist to improve health care data collection for LGBTQ individuals, such as The LGBT Data Inclusion Act (United States Congress, 2017; 2019), the federal government does not legally obligate nor incentivize health organizations to collect data separately for LGBTQ patients (Gates, 2017). Current data collection has little value in discerning LGBTQ health and health care issues, nor does there appear to be incentives to secure data, due in large part to anti-LGBTQ political and cultural forces. By examining Community Health Needs Assessments (CHNAs) from health 
care organizations across Wisconsin, we assess whether organizations gather data on sexual and gender minorities and whether urban and rural health care organizations differ in their collection of such data.

\section{LGBTQ DEMOGRAPHICS AND HEALTH CARE}

According to the Williams Institute (2019), 4.5\% of the population identifies as LGBTQ and 2.9 to 3.8 million LGBTQ individuals live in rural communities. Collection of LGBTQ specific data is vital as LGBTQ individuals suffer at higher rates than heterosexuals from limitations on access to health care (Joint Commission, 2011). Regardless of location, access to quality, culturally competent care for LGBTQ individuals is considerably lower than for heterosexual and cis-gender individuals (Fisher, Irwin, \& Coleman, 2014: Loftus, Allen, Call, \& Everson-Rose, 2018). Additionally, LGBTQ individuals fare significantly worse in rural communities (Caldwell, Ford, Wallace, Want, \& Takahashi, 2016; Dahl, Scott, \& Peace, 2015; Fisher, Irwin, \& Coleman, 2014; Horvath, Iantaffi, Swinburne-Romine, \& Bockting, 2014; Rosenkrantz, Black, Abreu, Aleshire, \& Fallin-Bennett, 2017; Rowan, Giunta, Grudowski, \& Anderson, 2013).

\section{BUILDING CAPACITY}

Building LGBTQ capacity is crucial in terms of data collection as heteronormative assumptions concerning both gender identity and sexual orientation can have harmful effects on access to and care of LGBTQ and gender non-conforming individuals (Bauer, Hammond, Travers, Kaay, Hohenadel, \& Boyce, 2009; Wheeler \& Dodd, 2011). The Joint Commission illustrates the significant need of quality care for LGBTQ individuals as well as providing a set of detailed guidelines for policy and organizational capacity building in its 2011 report, Advancing Effective Communication, Cultural Competence, and Patient- and Family-Centered Care for the Lesbian, Gay, Bisexual, and Transgender (LGBT) Community: A Field Guide (hereafter referred to as Field Guide).

Although the early literature on capacity and capacity building is often discussed as management or organizational capacity (Burgess, 1975), Gargan (1981) argued that "simply put, ... capacity is its [organization's] ability to do what it wants to do" (p. 652) subject to internal (administrative) as well as external factors, such as the interaction of a community's expectations, resources, and problems. The capacity-building approach (Wang, Hawkins, Lebredo, \& Berman, 2012) incorporates much of the previous theory and research regarding capacity building and provides a useful model by which to better understand the barriers to LGBTQ capacity building. It also recognizes the need to develop political support, technologies, financial resources, and managerial execution in order to build organizational capacity for policy change. As such political capacity includes the level of support from stakeholders, which includes managers and employees as well as the business and nonprofit community, either of which could potentially derail any LGBTQ initiatives.

\section{DATA AND METHODS}

We examined publicly available CHNAs, which are mandated by the Affordable Care Act of 2010 from health care organizations across Wisconsin for evidence of consideration of the special needs of LGBTQ populations. ${ }^{2}$ According to the Center for Disease Control (2018): “A community health assessment, also known as community health needs assessment, refers to a state, tribal, local, or territorial health assessment that identifies key health needs and issues through systematic, comprehensive data collection and analysis." CHNAs often focus on health conditions rather than specific demographics or disparities, but they do provide at least a summary of the data used to determine an organization's health care priorities. CHNAs are usually conducted every three years and so no older than 2016 were acquired for nearly all the hospitals that are members of the Wisconsin Hospital Association. Overall, 115 CHNAs representing 150 Wisconsin health care organizations (hospitals, medical centers/clinics, and health departments) were analyzed. 
To facilitate this exploration, CHNAs were individually culled for specific information. First, each CHNA was coded according to how it treated the concepts of gender and sexual orientation. Secondly, as per the Joint Commission (2011) recommendation that health care organizations "avoid assumptions about sexual orientation and gender identity" (p. 12), each CHNA also was coded according to whether the community survey tool (including interview questionnaires) was included and how the concept of gender/orientation was asked either in the community survey or interview questionnaire.

Next, a word search was conducted for the following words: LGBT (or some variant), transgender, gay, lesbian, bisexual, queer, and gender non-conforming (or some variant). For each term, responses were coded as either 0 for "no mention" and 1 for " 1 or more mentions." For those CHNAs that included at least one of the search terms, how the term was employed was also coded. This included whether the terms were used as part of the community demographics or discussed in terms of sampling or listed as a community stakeholder. If the LGBTQ (sexual or gender minorities) term was employed in some other way to comment/explain some aspect of the data or the medical priorities, as outlined by the Joint Commission (2011) recommendation, at least indirectly, that health care organizations "provide information and guidance for the specific health concerns facing lesbian and bisexual women, gay and bisexual men, and transgender people" (p. 15), it was coded as a comment. Lastly, if there was a section or subsection specifically addressing the LGBTQ population, it was coded as LGBT Section.

To account for possible cultural differences in rural and urban health care (Loftus, Allen, Call, \& Everson-Rose, 2018), each CHNA was coded according to whether it included other hospitals, clinics or health departments (shared or not) and whether in the compilation of the CHNA and the health care organization was located in a metropolitan or non-metropolitan county (based on the United States Department of Agriculture (2019) Rural-Urban Commuting Area codes (RUCA). The RUCA codes were consolidated from 9 to 3 categories: metro, urban and rural. Metro included the following 3 RUCA codes: "Metro-Counties in metro areas of 1 million population or more," "Metro-Counties in metro areas of 250,000 to 1 million population," and "Metro-Counties in metro areas of fewer than 250,000 population." Urban included the following RUCA codes: "Nonmetro-Urban population of 20,000 or more, adjacent to a metro area," "Nonmetro-Urban population of 20,000 or more, not adjacent to a metro area," "NonmetroUrban population of 2,500 to 19,999, adjacent to a metro area," and "Nonmetro-Urban population of 2,500 to 19,999 , not adjacent to a metro area." Rural included the following codes: "Nonmetro-Completely rural or less than 2,500 urban population, adjacent to a metro area" and "Nonmetro-Completely rural or less than 2,500 urban population, not adjacent to a metro area." Cross-tabulations were conducted to determine whether there exists a significant difference between rural and urban (metro/urban/rural) consideration of LGBTQ populations.

\section{Findings}

We assessed 115 CHNAs representing 150 Wisconsin health care organizations. Of these, $78 \%$ (which accounts for $75 \%$ of the health orgs) did not mention any of the LGBT terms. As illustrated in Table 1, transgender appeared most frequently followed by LGBT or LGBTQ. Of the remaining terms, lesbian and gay, appearing an equal number of times, was next followed by bisexual, gender non-conforming, and queer appearing least. Given that collection of such data is not mandated by law, this result was not unexpected.

\section{TABLE 1 MENTION OF LGBTQ TERMS IN CHNA}

\begin{tabular}{|l|c|c|}
\hline Term & CHNA Only & Health Care Org. \\
\hline Did Not Mention & $90(78.26 \%)$ & $113(75.33 \%)$ \\
\hline Did Mention & $25(21.74 \%)$ & $37(24.67 \%)$ \\
\hline LGBT & 15 & 25 \\
\hline Transgender & 19 & 31 \\
\hline Gay & 11 & 12 \\
\hline
\end{tabular}




\begin{tabular}{|c|c|c|}
\hline Lesbian & 11 & 12 \\
\hline Bisexual & 10 & 11 \\
\hline Gender Non-Conforming & 8 & 10 \\
\hline Queer & 5 & 5 \\
\hline $\begin{array}{r}\text { Total } \\
\end{array}$ & $115(100 \%)$ & $150(100 \%)$ \\
\hline
\end{tabular}

Only $20 \%$ of the CHNAs included surveys in the publicly available CHNA document (Table 2). A number of CHNAs included survey demographics, but we did not make assumptions about the exact wording of questions when only the resulting data was offered. A few CHNAs did include screenshots of a question's responses based on the available answers. Of the 21 surveys the authors were able to examine, nine offered only male or female options under gender. An additional four offered as options either male, female, and prefer not to answer (1) or male and female plus other (3), and one survey offered male, female, other, and prefer not to answer. four surveys included a transgender option (trans-male and trans-female) and three surveys that included no gender question at all. The community surveys that included the transgender option were the only surveys that also included a sexual orientation question (heterosexual, homosexual, bisexual) as well.

TABLE 2

INCLUSION OF GENDER AND/OR SEXUAL ORIENTATION

\begin{tabular}{|l|c|c|}
\hline Gender & CHNA Only & Health Care Orgs. \\
\hline Binary Only & $9(7.83 \%)$ & $16(10.67 \%)$ \\
\hline Binary \& "Prefer not to answer" & $1(0.87 \%)$ & $1(0.67 \%)$ \\
\hline Binary \& "Other" & $3(2.61 \%)$ & $3(2.00 \%)$ \\
\hline "Other" \& "Prefer not to answer" & $1(0.87 \%)$ & $1(0.67 \%)$ \\
\hline Transgender & $4(3.48 \%)$ & $5(3.33 \%)$ \\
\hline No Gender Question & $3(2.61 \%)$ & $3(2.00)$ \\
\hline Survey not included & $94(81.74 \%)$ & $121(80.67 \%)$ \\
\hline Total & 115 & 150 \\
\hline & & Health Care Org. \\
\hline Sexual Orientation & CHNA Only & $4(2.67 \%)$ \\
\hline All & $3(2.61 \%)$ & $25(16.67 \%)$ \\
\hline No sexual orientation question & $18(15.65 \%)$ & $121(80.67 \%)$ \\
\hline Survey not included & $94(81.74 \%)$ & 150 \\
\hline Total & 115 & \\
\hline Source: Authors' analysis of 115 Wisconsin Community Health Needs Assessments \\
\hline
\end{tabular}

Of note was an interview schedule that asked the interviewer to ascertain each interviewee's gender, as indicated by the interview scripting "[DERIVED, NOT ASKED]" displayed in Figure 1. There is no indication that interviewers chose any gender other than male and female as these were the only choices available to record. Such a practice is in direct contradiction to the Joint Commission (2011) directive to "avoid assumptions about sexual orientation and gender identity" (p. 12). 


\section{FIGURE 1 \\ INTERVIEW SCHEDULE QUESTION}

\section{Gender [DERIVED, NOT ASKED]}

Male. $48 \%$

Female 53

Source: City of Milwaukee Community Health Survey Report, 2018 (p. 43).

Less than twenty-five percent of the CHNAs examined from Wisconsin mentioned one of the LGBTQ terms, and Table 3 displays the results of cross-tabulations of LGBTQ term mentions by location type (metro, urban, rural). Pearson Chi-Square results indicate that there is not a significant difference by location type, suggesting there is little difference in consideration of LGBTQ populations in health care planning. This indicates both rural and urban areas need to do better in the collection LGBTQ data. It does appear that the LGBTQ terms were included more in smaller metro areas but as noted earlier, not is not a significant difference. Rural areas did not include any of the terms, which corresponds to commonly held assumptions about rural environments, yet the scant few LGBTQ term mentions within larger metropolitan areas contradicts analogous assumptions.

TABLE 3 MENTION OF LGBTQ TERMS ON CHNA BY METRO/URBAN/RURAL AREA

\begin{tabular}{|c|c|c|c|}
\hline & Mentioned & $\begin{array}{l}\text { Did Not } \\
\text { Mention }\end{array}$ & Total \\
\hline $\begin{array}{l}\text { Metro: Counties in metro areas of } 1 \text { million population or } \\
\text { more; Counties in metro areas of } 250,000 \text { to } 1 \text { million } \\
\text { population, and Counties in metro areas of fewer than } \\
250,000 \text { population. }\end{array}$ & 13 & 49 & 62 \\
\hline $\begin{array}{l}\text { Urban: Nonmetro urban population of } 20,000 \text { or more, } \\
\text { adjacent to a metro area; Nonmetro-Urban population of } \\
20,000 \text { or more, not adjacent to a metro area; Nonmetro- } \\
\text { Urban population of } 2,500 \text { to } 19,999 \text {, adjacent to a metro } \\
\text { area; and Nonmetro-Urban population of } 2,500 \text { to } 19,999 \text {, } \\
\text { not adjacent to a metro area. }\end{array}$ & 13 & 33 & 46 \\
\hline $\begin{array}{l}\text { Rural: Nonmetro-Completely rural or less than } 2,500 \text { urban } \\
\text { population, adjacent to a metro area" and "Nonmetro- } \\
\text { Completely rural or less than } 2,500 \text { urban population, not } \\
\text { adjacent to a metro area. }\end{array}$ & 0 & 6 & 6 \\
\hline TOTAL & 26 & 88 & $114^{\mathrm{a}}$ \\
\hline \multicolumn{4}{|c|}{$X^{2}(7)=2.669$} \\
\hline
\end{tabular}

Next, how both the examined terms and LGBTQ individuals themselves were considered within the context of the CHNA was assessed. Table 4 displays the frequency of how the terms were used in the CHNA, though as the issue was addressed previously, the table does not include whether it was mentioned on the community survey. CHNAs used LGBTQ terms in a variety of ways. One CHNA only included the term in the community survey in the appendix (Cumberland Health Care, 2018). Four CHNAs used LGBTQ terms as part of the sample for either community surveys or focus groups while eight CHNA's included the 
terms as part of their community demographics (Gunderson Boscobel Hospital \& Clinics, 2018; Crawford County and Grant County, 2018; Crossing Rivers Health Medical Center, 2018; Ripon Medical Center, 2018; Southwest Health, 2019; Waupun Memorial Hospital, 2018). The most common example was inclusion of transgender and/or gender non-conforming individuals with male and female in reporting demographics (e.g., Gunderson Boscobel Hospital \& Clinics, 2018). There were also a few CHNAs that included demographics (albeit limited) on sexual orientation (e.g., Ripon Medical Center, 2018).

\section{TABLE 4 HOW LGBTQ TERMS EMPLOYED IN CHNA}

\begin{tabular}{|l|c|c|}
\hline Gender & CHNA Only & Health Care Org. \\
\hline Demographics & 8 & 10 \\
\hline Stakeholder & 2 & 6 \\
\hline Sample & 4 & 4 \\
\hline Comment & 3 & 21 \\
\hline \multicolumn{2}{|l|}{ LGBT Section } & 3 \\
\hline $\begin{array}{l}\text { Note: A total is not included as the various terms could appear multiple times/ways in any given CHNA. } \\
\text { Source: Authors' analysis of the 25 Wisconsin Community Health Needs Assessments that included LGBTQ terms. }\end{array}$ \\
\hline
\end{tabular}

Comments concerning LGBTQ populations in regard to some aspect of the CHNA, whether concerning a particular priority or discussion of health disparities, appear in 14 CHNAs. Three CHNAs (Ripon Medical Center, 2018; St. Agnes Hospital, 2018; and Waupun Memorial Hospital, 2018), which all utilized the Fond du Lac County Health Report (2018) reported that focus group input from LGBTQ+ individuals suggested efforts by health care providers could be more targeted and specifically noted transgender individuals experience great difficulty finding providers. Examples related to healthcare priorities included Ashland Memorial Hospital, which stated among its objectives that "By 2020, reduce the disparities in unhealthy and risky alcohol and other drug use among populations of differing races, ethnicities, sexual identities and orientations, gender identities, and educational or economic status" (Ashland Memorial Hospital, 2018 p.10; see also Fort Atkinson, 2018, p. 42). Similarly, Tomah County's needs assessment stated, "Within the state of Wisconsin, people who identify as LGBTQ, are African American or Native American, or have a disability are more likely to report that they currently smoke" (Tomah Compass Now, 2018, p.42). Other examples included mention of LGBT populations concerning mental or behavioral health (Aspirus Riverview Hospital, 2017; Roger's Behavioral Health, 2019; Southwest Health, 2019 ThedaCare Regional Medical Center Appleton, 2016; ThedaCare Regional Medical Center Neenah, 2016,). Lastly, three CHNAs include a section or subsection specifically concerning LGBTQ populations that contained more detailed information concerning LGBTQ populations, particularly as it relates to either health priorities, disparities, or both (Southwest Health, 2019, pp. 35-36; ThedaCare Regional Medical Center Appleton, 2016, p. 20; ThedaCare Regional Medical Center Neenah, 2016, p. 20).

\section{DISCUSSION AND RECOMMENDATIONS}

Although the focus of this research is narrow, the mention of LGBTQ terms in health care systems' CHNAs has widespread implications concerning health care policy and health care for LGBTQ individuals. There are several recommendations from the Joint Commission's (2011) Field Guide particularly relevant to this research and data collection.

\section{Provision of Care, Treatment, and Services}

A recommendation related to the provision of care that is directly relevant to data collection is "Avoid assumptions about sexual orientation and gender identity." This has implications for data collection all levels, whether as part of the CHNA, meeting with the physician, to checking ion for an appointment. Over $80 \%$ of Wisconsin health care organizations did not question cis-gender and heteronormative assumptions. 
LGBTQ disparities are significant and can only be addressed if organizations acknowledge contemporary understandings of sexuality and gender. Furthermore, given political and institutional bias, an impactful opportunity exists for health care organizations to lead systemic change necessary to stimulate and provide precedent for policy changes at the state and national level.

Building capacity to improve safety and quality for LGBTQ patients requires recognizing their presence within the population served by the respective health care system and the fact they constitute a unique demographic segment (Bauer, et al., 2009; Gates, 2013; Moore \& Dukes, 2019; Wheeler \& Dodd, 2011). As stated in one CHNA:

Gender is a form of social identity that may or may not align with sex assigned at birth, (e.g., female, male, or intersex). Gender categories are non-binary and encompass a spectrum of experiences, such as those who identify as women, men, transgender, and genderqueer. ... Given gender-based discrimination, these norms position individuals with differential access to income, education, and power according to gender identity. ...As noted there, data were only available for the population female and male, and nonbinary options were not included. (Aspirus Riverview Hospital, 2017, p. 29)

In order to provide quality care to all individuals, healthcare systems must operate with the understanding gender is not only non-binary but also fluid and heterosexuality is not universal (see Bauer, Braimoh, Scheim, \& Dharma, 2017 and Galupo, Lomash, \& Mitchell (2017) for discussion of more inclusive scales concerning gender identity and sexual orientation). Federal and state government entities must also do more from a policy and regulatory standpoint to ensure LGBTQ individuals are seriously considered in health care decision-making and health care policy.

\section{Data Collection and Use}

Two relevant recommendations directly concerning data collection and use include "Identify opportunities to collect LGBT-relevant data and information during the health care encounter" and "Use available population-level data to help determine the needs of the surrounding community." In making these recommendations, the Joint Commission recognizes LGBTQ populations and associated disparities as well as recognizing the need to collect better data. The lack of measurement of even the most basic information about local LGBTQ populations is in essence erasure and greatly effects these individuals' ability to access health care services (Bauer et. al. 2009, p. 353, see also Rattay, 2019 for a detailed discussion of this issue). Several health care systems/hospitals used available survey data such as the Wisconsin 2017 Transgender Community Needs Assessment and/or commented on the need for better data regarding LGBTQ populations.

Given institutional bias regarding the collection of data concerning gender identity and sexual orientation, it is necessary for local health care systems to collect such data either through community surveys or patient interactions, if possible (Moore \& Dukes, 2019). Two health care systems collected primary data or used additional information concerning LGBTQ populations. As part of Dane County's qualitative data collection, data was collected specifically from transgender individuals and Outreach Community Center email interviews (p. 14) as well as drawing on information from the "2017 Wisconsin Transgender Youth Community Needs Assessment." Southwest Health also made extensive use of the 2017 Wisconsin Transgender Youth Community Needs Assessment as well as collecting their own data regarding sexual minorities as part of their community survey (Southwest Health, 2019, p. 47).

County-level population data was used by all but very few health care systems/hospitals, yet many acknowledge its limitations. Local level data was recognized as especially important for LGBTQ populations due to high impact health disparities, such as mental health and substance abuse issues (Southwest Health, 2019; ThedaCare Regional Medical Center Appleton, 2016; ThedaCare Regional Medical Center Neenah, 2016). Efforts to address these problems can be enhanced with more attuned primary and secondary data collection, as suggested by the recommendation, "Identify opportunities to collect LGBT-relevant data and information during the health care encounter." These opportunities include 
not only health systems' consideration of their own patient databases but also improved efforts to accurately record gender and sexuality during health care encounters, among other sources and collection opportunities. Furthermore, data collection could be greatly enhanced if care is taken to develop protocol and provide staff and practitioners the cultural competence training needed to create an affirming health care environment in which LGBTQ individuals feel comfortable disclosing accurate information regarding gender identity and sexual orientation.

\section{Patient, Family, and Community Engagement}

Improved data collection on LGBTQ populations is both important and necessary for other Field Guide's recommendations, such as to "collect feedback from LGBT patients and families and the surrounding LGBT community," which is related to engagement with the community as well as current and future patients and loved ones. Community health care organizations take seriously their responsibility to understand and serve their populations and their changing needs. Given the intention behind the CHNA process, it is expected that genuine community engagement is necessary to that process, and therefore, attention must be focused to ensure local level population data and feedback are collected from the surrounding communities, particularly those from vulnerable populations, such as LGBTQ individuals. Populations served by all health care organizations are naturally diverse, and the existence of minorities in any population naturally demands increasing attention to disparities. Better data collection throughout the CHNA process will help health care organizations address health care disparities, which can otherwise seriously limit any gains in quality of care and the quality of health and life among the broader population while also resulting in unnecessary additional costs.

Given the array of entrenched institutional barriers, dramatic change is unlikely, regardless of the need. However, even the mere mention - a recognition - that current data collection is limited by heteronormative and gender bias as well as the lack of institutional support of data collection on LGBTQ populations is a key step forward, without which health care organizations are simply unable to even begin addressing and effectively reducing health care disparities among their LGBTQ population. That simple acknowledgement by the leadership of health care organizations - whether hospitals, health departments, or other health care related organizations and agencies - would acknowledge the gravity of this issue and inspire change. Despite institutional barriers, some health care organizations, due in large part to conscientious and dedicated health care professionals, are taking action to address the severe data collection problems. More is needed.

\section{CONCLUSION}

Few health care systems significantly consider LGBTQ populations. As these and other organizations around the nation strive to provide quality health care and patient safety, their success will rest in part on how diligently they strive to remove the effects of implicit and institutional bias, in spite of the political and institutional barriers that historically have resulted in the ill-treatment of many in the LGBTQ population. Future research will continue to examine these issues beyond the CHNA to include the process for developing the implementation plan.

\section{ENDNOTES}

1. The authors would like to thank Dr. Gregory Lewis for his helpful feedback on an earlier draft of this research project.

2. A list of all the available CHNAs used as well as the affiliated health care organizations is available from the authors. 


\section{REFERENCES}

Bauer, G.R., Hammond, R., Travers, R., Kaay, M., Hohenadel, K.M., \& Boyce, M. (2009). “I don't think this is theoretical; This is our lives": How erasure impacts health care for transgender people. JANAC: Journal of the Association of Nurses in AIDS Care, 20(5), 348-361.

Bauer, G.R., Braimoh, J., Scheim, A.I., \& Dharma, C. (2017). Transgender-inclusive measures of sex/gender for population surveys: Mixed-methods evaluation and recommendations. PLOS ONE, 12(5), e0178043.

Boehmer, U. (2002). Twenty years of public health research: Inclusion of lesbian, gay, bisexual, and transgender populations. American Journal of Public Health, 92, 1125-1130.

Burgess, P. (1975). Capacity Building and the Elements of Public Management. Public Administration Review, 35, 705-716.

Caldwell, J.T., Ford, C.L., Wallace, S.P., Want, M.C., \& Takahashi, L.M. (2016). Intersection of living in a rural versus urban area and race/ethnicity in explaining access to health care in the United States. American Journal of Public Health, 106(8), 1463-1469.

Centers for Disease Control and Prevention. (2018). Community Health Assessment \& Health Improvement Planning. Retrieved from https://www.cdc.gov/publichealthgateway/cha/index.html

Dahl, A., Scott, R., \& Peace, Z. (2015). Trials and triumph: Lesbian and gay young adults raised in a rural context. Social Sciences, 4(4), 925-939.

Denney, J.T., Gorman, B.K., \& Barrera, C.B. (2013). Families, resources, and adult health: Where do sexual minorities fit. Journal of Health and Social Behavior, 54, 46-63.

Fisher, C.M., Irwin, J.A., \& Coleman, J.D. (2014). LGBT health in the midlands: A rural/urban comparison of basic health indicators. Journal of Homosexuality, 61, 1062-1090.

Galupo, M.P., Lomash, E., \& Mitchell, R.C. (2017). "All of My Lovers Fit Into This Scale”: Sexual Minority Individuals' Responses to Two Novel Measures of Sexual Orientation. Journal of Homosexuality, pp. 146-147.

Gargan, J. (1981). Consideration of Local Government Capacity. Public Administration Review, 41(6), $649-658$.

Gates, G.J. (2013). Demographics and LGBT health. Journal of Health and Social Behavior, 54(1), 7274.

Gates, G.J. (2017). LGBT Data Collection Amid Social and Demographic Shifts of the US LGBT Community. Am J Public Health, 107(8), 1220-1222.

Glasgow, J. (2019). Why count and measure? Delaware Journal of Public Health, 5(3), 64-66.

Horvath, K.J., Iantaffi, A., Swinburne-Romine, R., \& Bockting, W. (2014). A comparison of mental health, substance use, and sexual risk behaviors between rural and non-rural transgender persons. Journal of Homosexuality, 61(8), 1117-1130.

Joint Commission. (2011). Advancing Effective Communication, Cultural Competence, and Patient-and Family-Centered Care for the Lesbian, Gay, Bisexual, and Transgender (LGBT) Community: A Field Guide.

Kadour, R. (2005). The power of data, the price of exclusion. Gay \& Lesbian Review, 12(1), 31-33.

Loftus, J., Allen, E.M., Call, K.T., \& Everson-Rose, S.A. (2018). Rural-urban differences in access to preventive health care among publicly insured Minnesotans. The Journal of Rural Health: Official Journal of the American Rural Health Association and the National Rural Health Care Association, 34(Suppl 1), s48-s55.

Moore, C., \& Dukes, C. (2019). The value of identity: providing culturally responsive care for LGBTQ+ patients through inclusive language and practices. Delaware Journal of Public Health, 5(3), 6-9.

Rattay, K.T. (2019). LGBTQ population is needed to improve health care and reduce health disparities. Delaware Journal of Public Health, 5(3), 24-26.

Rosenkrantz, D.E., Black, W.W., Abreu, R.L., Aleshire, M.E., \& Fallin-Bennett, K. (2017). Health and health care of rural sexual and gender minorities: A systematic review. Stigma and Health, 2(3), 229-243. 
Ross, L.E., Salway, T., Tarasoff, L.A., MacKay, J.M., Hawkins, B.W., \& Fehr, C.P. (2018). Prevalence of depression and anxiety among bisexual people compared to gay, lesbian, and heterosexual individuals: A systematic review and meta-analysis. The Journal of Sex Research, 55(4-5), 435456

Rowan, N.L., Giunta, N., Grudowski, E.S., \& Anderson, K.A. (2013). Aging well and gay in rural America: A case study. Journal of Gerontological Social Work, 56(3), 185-200.

United States Congress. (2017). H.R. 3273 - LGBT Data Inclusion Act. Retrieved from https://www.congress.gov/bill/115th-congress/house-bill/3273

United States Congress. (2019). S. 1980 - LGBT Data Inclusion Act. Retrieved from https://www.congress.gov/bill/116th-congress/senate-bill/1980

United States Department of Agriculture. (2019). 2010 Rural-Urban Commuting Area (RUCA) Codes. Revised 2019. Retrieved from https:// www.ers.usda.gov/data-products/ rural-urban-commutingarea-codes/ documentation/

Wang, X., Hawkins, C., Lebredo, N., \& Berman, E. (2012). Capacity to Sustain Sustainability: A Study of U.S. Cities. Public Administration Review.

Wheeler, D.P., \& Dodd, S.J. (2011). LGBTQ capacity building in health care systems: A social work imperative. Health \& Social Work, 36(4), 307-309.

Williams Institute. (2019). LGBT and same-sex demographics in the US. Retrieved from https://williamsinstitute.law.ucla.edu/lgbtstats/ 